\title{
Exploration of Ideological and Political Education in College Physics
}

\author{
Jiazhong $\mathrm{He}^{1, *}$ and Zhilong Zhong ${ }^{1}$

\begin{abstract}
${ }^{1}$ School of Intelligent Engineering, Shaoguan University, Shaoguan, Guangdong 512005, China
*Corresponding author. Email: hejiazhong@126.com
\end{abstract}

\begin{abstract}
Ideological and political education (IPE) of the curriculum is an important way to integrate IPE into curriculum teaching and realize all-round education. The integration of IPE elements into college physics teaching is the practice of the new IPE concept. This paper first analyzes the advantages and necessity of IPE in college physics, then analyzes the current situation of IPE in college physics at this stage, and finally discusses the implementation strategies of IPE in college physics teaching, and puts forward specific methods and ways to implement IPE.
\end{abstract}

Keywords: college physics, ideological and political education( IPE), teaching practice, curriculum teaching

\section{INTRODUCTION}

General secretary $\mathrm{Xi}$ Jinping stressed at the national conference on ideological and political education (IPE) in colleges and universities that the IPE of colleges and universities is related to the fundamental question of what kind of people the colleges and universities cultivate, how to cultivate them, and for whom. It is necessary to persist in taking the morality and cultivating of people as the central link, putting IPE throughout the whole process of education and teaching, to realize the whole process of educating people and all-round education, and strive to create a new situation in the development of my country's higher education. We should make good use of the main channel of classroom teaching and strengthen the IPE theory course in the improvement. We should improve the affinity and pertinence of IPE to meet the needs and expectations of students' growth and development. Other courses should protect their channel and cultivate their responsibility field, so that all kinds of courses are in the same direction as theory courses of IPE, forming a synergistic effect. The Ministry of education proposed to strengthen the IPE of curriculum and specialty in the "opinions on accelerating the construction of high-level undergraduate education and comprehensively improving the ability of personnel training"[1]. In the process of constructing the full staff, the whole process and the allround education, we should make great efforts to promote the ideological and political construction of the curriculum in colleges and universities, do a good job in the overall design, and scientifically and rationally design the IPE content according to the characteristics of personnel training and the requirements of professional ability and quality[2]. It is necessary to strengthen every teacher's awareness of moral education, organically integrate the elements of IPE into each professional course, launch a batch of excellent professional courses with remarkable educational effect, create a batch of IPE demonstration classes, select several excellent IPE teachers, and form an educational pattern in which the professional course teaching and IPE theory teaching are closely linked to each other[3].

IPE means that all courses in colleges and universities have the function of IPE, which requires us to explore the IPE elements and functions contained in various courses in colleges and universities, effectively integrate into all aspects of classroom teaching, and realize the organic unity of IPE and knowledge system education. The effective integration of IPE into course teaching does not change the nature of course teaching. But in the course teaching, we should pay attention to excavate the IPE elements contained in the professional knowledge system itself, effectively integrate into the course teaching, improve students' professional spirit and social responsibility, stimulate students' endogenous learning motivation, and improve teaching quality. In teaching, we should use various means such as classroom teaching and extracurricular activities to cultivate students' noble ideology, morality and values, and spread the standard social values such as Marxist ideals and beliefs, socialist core values and excellent culture. Based on the analysis, judgment, selection and absorption, college students can internalize them into their own quality cultivation and externalize them into specific behavior habits, so as to realize the value guidance for students[4]. Physics is a discipline that studies the basic structure, interaction, the most basic and universal mode of motion and the law of mutual transformation of matter. The basic theories of physics permeate all fields of natural sciences and are applied to various departments of production technology. They are the foundation of natural sciences and engineering technology. The basic concepts, theories, methods and experimental skills taught in college physics course are not only an important part of college students' scientific literacy, but also the basic physical knowledge that a scientific and technological worker needs to know 
and understand. Therefore, college physics is a compulsory basic course for science and engineering students. The course of college physics contains a strong sense of patriotism, dialectical materialism and lofty moral quality education. As long as the teachers can deeply explore and make full use of the hidden materials of IPE contained in this course, they can effectively implement the IPE in this course[5,6].

In the teaching of college physics, how to excavate the potential IPE elements in the course, how to infiltrate the IPE concept into the teaching activities of basic knowledge and basic theory, how to integrate the humanistic quality education with the development of disciplines and majors, and lead students to form a correct outlook on life and values are the hot topics in the teaching reform of college physics under the IPE concept $[7,8]$.

\section{ADVANTAGES OF IMPLEMENTING IPE IN COLLEGE PHYSICS}

College Physics contains rich scientific thought, scientific method, scientific spirit, dialectical materialism world outlook and deep humanistic feelings. Through college physics classroom teaching and extracurricular activities, while teaching physics knowledge, in-depth exploration and integration of IPE elements can, on the one hand, make physics classes more vivid and interesting, and on the other hand, let the invisible IPE infiltrate students' minds. The advantages of implementing IPE in college physics are as follows[6,8]:

- College Physics is a public basic course for science and engineering majors. The wide range of benefits is a solid foundation for the integration of college physics and IPE elements.

- College Physics aims to cultivate students' thinking ability, scientific literacy, and scientific spirit, correct understanding of objective things, forming materialist world outlook, ability to solve practical problems and scientific research innovation ability. A clear teaching goal is an effective platform for the integration of college physics and IPE elements.

- Physics is a discipline that studies the movement and law of matter, and it is perfectly combined with Marxist material view. The teaching content of college physics is helpful to cultivate students' philosophical thoughts, especially to the cultivation of students' material outlook and world outlook.

- College Physics courses hide deep humanistic feelings, and the laws of physics contain rich humanistic values. The connection between physical knowledge and IPE elements will not only help students better understand abstract physical theories but also contributes to the cultivation of students' emotional goals.

Therefore, IPE in college physics is not only the need of college physics teaching reform, but also the practice of the new educational concept of IPE.

\section{THE CURRENT PROBLEMS OF IPE IN COLLEGE PHYSICS}

The implementation of IPE in college physics has many advantages and achieved certain results, but there are also some problems, mainly in the following aspects $[6,8]$ :

- Lack of institutional guarantee. The development plan, training program, educational goal and evaluation index of IPE in college physics are lack of the guarantee of the school system.

- Insufficient attention to thoughts. College Physics teachers have insufficient understanding of the IPE, insufficient ideological attention, and lack of awareness of integrating IPE into college physics.

- There is not enough entry point of IPE. Due to the long-term teaching habits, many professional teachers only pay attention to the teaching of knowledge in college physics, and lack the entry point of scientific and systematic IPE elements when teaching college physics knowledge.

- The teaching methods of IPE lack diversification. Teachers generally adopt the method of introducing the deeds of Chinese and foreign scientists to implement IPE. The teaching method is relatively simple, and the effect of IPE is not obvious.

\section{IMPLEMENTATION STRATEGY OF IPE IN COLLEGE PHYSICS}

College Physics needs to adapt to the requirements of the IPE concept to improve teaching methods and strategies and improve and revise the teaching evaluation system. The following discusses the IPE implementation strategies of college physics curriculum $[7,8]$.

\subsection{Embodying IPE in Teaching Objectives}

The overall objective of IPE in college physics includes[7,8]:

- Integrating socialist core values, excellent traditional Chinese culture education, environmental protection awareness, humanistic feelings, engineering ethics, and craftsman spirit, and so on into college physics teaching.

- To cultivate students' ability to observe, think and solve practical problems with physical ideas and methods;

- To cultivate the students' spirit of seeking truth from facts, proceeding from reality and integrating theory with practice;

- To cultivate students' scientific spirit of continuous exploration, brave climbing to the summit, continuous exploration, persistence and innovation; 
- To cultivate students' spirit of patriotism, the ideal and belief of realizing the Chinese dream.

The teaching objectives of college physics are divided into three levels[7,8]:

- Knowledge objective. To cultivate students to master the basic knowledge, thinking methods and basic principles of college physics.

- Ability objective. To cultivate students' ability of autonomous learning and knowledge transfer, the ability to analyze and solve problems, and certain experimental operation skills.

- Education objective. To cultivate students to establish a correct outlook on life, values and world outlook, and become a social responsibility people with sense of responsibility and mission.

In the teaching practice of college physics under the concept of IPE, we should integrate the educational objective, knowledge objective and ability objective scientifically, excavate the IPE elements appropriately and reasonably in the teaching design of knowledge and theory, and reflect the value guidance, knowledge imparting and ability cultivation into every link of teaching objectives, so as to make scientific philosophy and correct values infiltrate into the whole teaching process.

\subsection{Realizing IPE in Teaching Content}

The teaching process under the goal of ideological and political teaching needs to integrate the teaching content of college physics, and gradually highlight the ideological and political function in the process of restructuring and optimizing the content and knowledge[2]. In the selection of teaching content, the contents that meet the requirements of the times and promote the socialist core values are infiltrated into the classroom teaching to help students establish a correct outlook on life and values[7,8].

- The Chinese scientists' deeds should be used to guide students to learn the scientific spirit of scientists who love science, observe hard, dare to explore and persevere, and accept the influence of the great personality of scientists. To learn the excellent quality of scientists who study assiduously and work hard for the revitalization of the Chinese nation, inherit and carry forward their glorious tradition, stimulate students' interest in learning and enhance their scientific literacy.

- In the teaching, we should introduce the achievements of science and technology in ancient and modern China, enhance students' sense of national pride and patriotism, establish the confidence of climbing the peak of science and technology, and shoulder the responsibility of national rejuvenation[3].

- Introduce the history of physics, increase students' knowledge, let students take history as a mirror, help students form correct values, promote the organic integration of physical knowledge and IPE. There are many classic cases in the history of physics. Each case contains enlightening philosophy of life, which can convey the correct values to students, and then realize the value guidance for students.

- Through the teaching of the establishment process of physical theory, students can understand the formation process of physical concepts and laws, master its logical system, and more importantly, enable students to learn the scientific spirit of scientists who are fearless of difficulties and dangers, pursue truth, dare to innovate, and lead students to form a correct outlook on life and values;At the same time, learn the spirit of scientists not to be superstitious in authority, and to be brave in exploring the truth, cultivate students' creative thinking and critical thinking skills, and form a correct scientific outlook.

- Through college physics experiments, we can cultivate students' excellent qualities such as seeking truth from facts and teamwork. Physics is an experimental science. The physical experiment is the source of physical theory and the foundation of engineering technology, which embodies the commonness of most scientific experiments. Physics is an experimental science, and physical experiments are the source of physical theory and the foundation of engineering technology. College Physics experiment course has rich experimental ideas, methods and means, which can provide students with comprehensive experimental skills training, cultivate students' scientific experimental ability and improve their scientific literacy. Physical experiment courses can cultivate students' rigorous attitude, teamwork ability, theory with practice and comprehensive application ability to adapt to the development of science and technology. The abilities and accomplishments acquired through physics experiments are excellent qualities that students need for future work[7,8].

\subsection{Optimize the Evaluation of IPE in College Physics}

Teaching evaluation is an activity to evaluate the teaching process and effect according to teaching objectives and serve for teaching decision-making. Teaching evaluation generally includes the evaluation of students' learning effect and the evaluation of teachers' teaching process[7,8].

- The basic principle of IPE is to carry out various teaching activities around the correct political direction, resolutely implement the party's and state's education policy, and cultivate physical and mental health talents. For teachers, the evaluation of IPE in college physics is not only the evaluation of teaching professional knowledge and skills, but also the evaluation of spreading socialist core values; For students, it is not only the evaluation of learning professional knowledge and skills, but also the evaluation of establishing a correct world outlook, outlook on life and socialist core values. 
- The teaching evaluation of IPE in college physics requires teachers to put the evaluation of serving the educational goal in the first place, to infiltrate the cultivation of correct outlook on life and values into the whole teaching process, and to establish and improve the teaching evaluation system in line with the healthy development of students' body and $\operatorname{mind}[5]$.

To realize the connection between college physics teaching and IPE, and to give full play to the role of IPE, it is necessary to ensure that the college physics teaching under the IPE concept is based on a scientific evaluation and feedback mechanism. According to the specific requirements, objectives, tasks, results and other elements of IPE in college physics, the school should establish a targeted evaluation and feedback system. While investigating students' studies, we should strengthen the evaluation of students' learning attitude, ideological awareness, professional quality, scientific research spirit and practical ability. The effectiveness of college physics teaching under the concept of IPE is evaluated through regular assessment of education effect, so as to continuously optimize and improve the existing education mode, and realize the effective penetration of IPE in physical education[7,8]

\subsection{Strengthening the Construction of Teachers' Team in IPE}

The mission of university teachers is not only to impart professional knowledge and skills, but also to spread advanced ideology and culture, to teach correct world outlook, values, and outlook on life, to plant the "seed" of socialist core values in students' hearts, and to perform the sacred duty of disseminating knowledge, skills, thoughts, and truth. The teacher's job is not only to spread physics knowledge, thoughts, and truth, but more importantly, to shape the soul, character and personality of students[6,8].

- Teachers should have a correct political stand and firm political consciousness, fulfill their original intention of teaching and educating people, and take the responsibility of cultivating socialist builders and successors.

- Teachers should carry out the education concept of people-oriented and moral education first, establish morality and cultivate people, improve the quality of students, and promote the overall development of students

- The IPE in college physics requires teachers to dig deep into the IPE elements in college physics, teach students the correct world outlook, outlook on life, values, thinking methods and so on, so as to imperceptibly complete the IPE.

- In order to realize the IPE of college physics, the construction of teachers is very important. Teachers should improve their understanding of the importance and necessity of IPE and improve the teaching ability of all teachers.

Colleges and universities should formulate corresponding rules and systems, strengthen the construction of teaching staff, provide professional guidance for teachers in IPE, eliminate the one-sided thought of teachers attaching importance to teaching books but neglecting moral education, and advocate collaborative education among different majors and different courses[8].

- The school arranges professional teachers of IPE for professional guidance and puts forward relevant IPE suggestions for teachers.

- Before teachers carry out IPE, the school arranges systematic training to better learn the theoretical knowledge of IPE.

- The school set up the research fund of IPE, encouraged the teachers of IPE to declare, and actively explored the IPE reform.

\section{CONCLUSION}

This paper explores the IPE in college physics, and discusses the teaching objectives, teaching contents, teaching evaluation and teaching staff construction. IPE in colleges and universities is not only the duty of ideological and political teaching staff and counselors, but also the responsibility of every teacher. As an important compulsory basic course of science and engineering in colleges and universities, it is particularly important to integrate IPE into the teaching because of the wide range of students. College Physics teachers should innovate their ideas, formulate scientific IPE objectives, excavate the IPE elements in college physics knowledge, and promote the organic integration of college physics and IPE.

\section{ACKNOWLEDGMENT}

This work was supported by the curriculum ideological and political construction project of Shaoguan University (2020), the education and teaching reform project of Shaoguan University (Grant No. SYJY20192033), the "Quality Engineering" construction project of Shaoguan University (2019), and the demonstration project of curriculum ideological and political construction reform in undergraduate universities of Guangdong Province (2020).

\section{REFERENCES}

[1] Y.Ni and Z. Guo, "The classroom practice exploration of ideological politics in college physics course," Education Teaching Forum, pp. 51-52, April 2020. (In Chinese)

[2] Y. Han, H. Li, and Sarengaowa, "Research on digging the ideological and political education resources 
in university physics courses," Journal of Inner Mongolia University for Nationalities, vol. 35(2), pp. 61-63, March 2020. (In Chinese)

[3] D. Xu, J. Zhang, L.Xie, and L. Sun, "Exploring the integration of curriculum ideological and political education into college physics teaching," Science \& Technology Vision, pp. 133-135, 2019. (In Chinese)

[4] Z. Liu, "Practical research and practice of ideological and political education in college physics," Journal of Hunan University of Humanities, Science and Technology, vol. 36(6), pp. 92-95, April 2019. (In Chinese)

[5] S. Li, "Taking engineering certification as the opportunity, strengthen the thought teaching research of university physics course," Education Teaching Forum, pp. 256-257, March 2020. (In Chinese)
[6] X.Xia, X.Cao, Y.Zhuo, and Y.Liang, "Research on ideological and political education in college physics course," The Guide of Science \& Education, vol. 34(12), pp.113-114, December 2018. (In Chinese)

[7] B. Liu, "Practice and thinking of teaching reform of college physics course under ideological and political course concept," Journal of Jiangsu Vocational Institute of Architectural Technology, vol. 19(2), pp.63-65, June 2019. (In Chinese)

[8] H.LI, C. LI, M.ZHANG, X. LIU, C.YUAN, B. ZHU, "Innovative Thoughts on Integrative Education of College Physics and Ideological and Political Elements," Education Teaching Forum, pp. 284-285, February 2020. (In Chinese) 